\title{
EM OUTRO PLANO DO SER: UMA POÉTICA DA DUPLICIDADE NA NARRATIVA FANTÁSTICA DE JULIO CORTÁZAR
}

\author{
Amanda Pérez Montañés
}

\section{RESUMO:}

Diversos relatos de Julio Cortázar apresentam uma predileção pelo excepcional, seja nos temas ou nas formas expressivas, impondo ao leitor um modo ambíguo e paradoxal de compreender a realidade, para além da percepção rotineira do "real". A situação causal específica, criada a partir de procedimentos narrativos, projeta uma nova luz sobre o fato banal, que dessa forma é transformado em acontecimento dual e surpreendente. Nessa operação metafísica se altera o sentido da percepção para estabelecer uma nova forma de pensamento que é paradoxal e subversivo do senso comum. Assim, pelo caminho do não sentido, o autor/leitor adentra num sistema mais complexo de relações, aglutinante de uma realidade infinitamente mais vasta em que se projetam dois planos do ser: um profundo e real, outro, multiplicidade infinita do vir a ser, vazio abismal no qual o duplo é incluído como habitante. A partir das anteriores considerações, objetiva-se neste estudo realizar uma reflexão poética sobre a presença do duplo na narrativa fantástica de Julio Cortázar, entendido esse conceito como sinônimo e correlato da ficção.

\section{PALAVRAS-CHAVE:}

Literatura Fantástica; Duplo; Relatos; Julio Cortázar.

\section{Na sala dos espelhos}

Na multiplicidade de possíveis percursos, a linguagem transforma o finito (a vida) em vastidão infinita (a ficção). O relato torna-se assim lugar de extravio porque, em sua errância, a escrita vai de um lugar a outro sem poder jamais se deter nem sair de seu próprio espaço. Ao chegar ao borde da linguagem, as palavras se detêm porque do outro lado não há nada, só vazio abismal, silencio. O limite infranqueável da linguagem é precisamente sua impossibilidade de nomear o inominável, revelando que o fato narrado só é uma invenção, e pelo mesmo aberto às possibilidades infinitas de criação e recriação da escrita, ou, como afirma Paz (1993, p. 580), "Em quanto escrevia o caminho de Galta se apagava ou eu me desviava e perdia em seus meandros. Uma e outra vez precisava voltar ao ponto de partida. Em vez de avançar, o texto girava sobre si mesmo".1

1 "A medida que escribía, el camino de Galta se borraba o yo me desviaba y perdía en sus vericuetos. Una y otra vez tenía que volver al punto de comienzo. En lugar de avanzar, el texto giraba sobre sí mismo". 


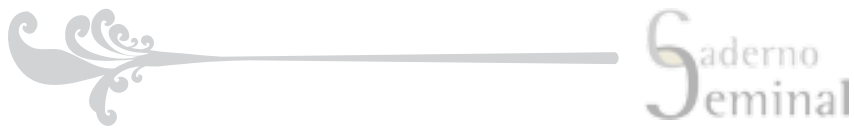

No eterno retorno da linguagem, a ficção aspira confundir-se com a realidade, porém, só é símbolo de um processo que de antemão tem sido definido como uma derrota: "realidade e ficção se enfrentam, se aniquilam mutuamente, abrem um vazio que só pode colmar outro relato possível"2 (PEZZONI, 1982, p. 45). No entanto, esse novo relato também é lembrança do vivido num mundo que só é representação, simulacro do real.

A realidade só existe porque as palavras a nomeiam. A linguagem se converte em mundo; e o mundo torna-se linguagem. "O mundo e o livro remetem um ao outro, eterna e infinitamente, suas imagens refletidas. Esse poder infinito de espelhamento, essa multiplicação cintilante e ilimitada [...] será, então, tudo o que encontraremos, no fundo de nosso desejo de compreender" (BLANCHOT, 2005, p. 138). No interior do relato se suspende o tempo real para dar lugar ao tempo fictício, no qual a escrita encontra seu lugar natural; início da linguagem, espaço virtual aberto a múltiplas possibilidades de representação no espelho da própria linguagem. Nessa duplicação infinita, a obra encontra sua dobra originaria que é autorrepresentação e redobramento:

A escrita significando não a coisa, mas a palavra, a obra de linguagem não faria outra coisa além de avançar mais profundamente na impalpável densidade do espelho, suscitar o duplo deste duplo que é já a escrita, descobrir assim um infinito possível e impossível, perseguir incessantemente a palavra, mantê-la além da morte que a condena, e liberar o jorro de um murmúrio33 (FOUCAULT, 1986, p. 9).

Construída na exterioridade do sentido, a escrita representa a fala, encarnação do logos e da razão, pretendendo assim dar conta da realidade. Porém, a escrita também é "representação de um território percorrido pelos fantasmas da noite e da morte, memória de um esquecimento que sempre será esquecimento da razão"4 (PEREIRA, 1985, p. 11), espaço do imaginário, do fantástico; labirinto de espelhos em que o homem pode encontrar seu ser multidimensional.

\section{Outros planos da realidade}

A literatura fantástica, entendida como uma forma privada da atopia constrói num mundo próprio e intenso a experiência de transformar o sentido imediato da realidade. Fundado sobre o lado noturno do homem (e não sobre o diurno), o fantástico coloca em xeque nossa forma de olhar o mundo ao revelar e representar a perturbação e a inquietação da experiência humana da modernidade. Fala sobre a interioridade do ser e a simbologia coletiva, por isso mesmo, carregado

\footnotetext{
2 "[...] realidad e invención se enfrentan, se aniquilan mutuamente, abren un vacío que sólo puede colmar otro relato posible"

3 "[...] la escritura, significando no la cosa sino la palabra, la obra de lenguaje, no haría otra cosa que avanzar más profundamente en este impalpable espesor del espejo, suscitar el doble de este doble que es ya la escritura, descubrir de esa manera un infinito posible e imposible, perseguir sin término la palabra, mantenerla más allá de la muerte que la condena, y liberar el centello de un murmullo".

4 "[...] escenificación de un territorio recorrido por los fantasmas de la noche y de la muerte, memoria de un olvido que será siempre el olvido de la razón".
} 


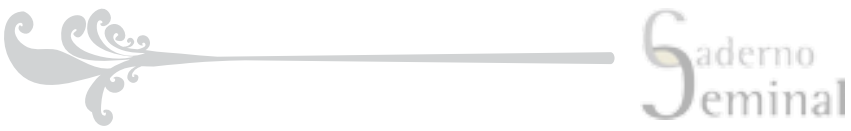

de sentido, oculta em seu interior o inconsciente reprimido atrás da aparência cotidiana dos fatos, "apresentando na forma de problemas, fatos anormais, irracionais ou irreais, em contraste com os fatos reais, normais ou naturais" 5 (BARRENECHEA, 1978, p. 90). O conflito ocorre quando os eventos anormais colidem contra a ordem da realidade, e é precisamente nessa fissura em que o fantástico se manifesta.

Na literatura fantástica hispano-americana do século $X X$, escritores como Jorge Luis Borges e Julio Cortázar se destacam, entre outros autores, na produção de obras primas do gênero. "O modo fantástico mostrou, em todo este período, uma extraordinária vitalidade, e capacidade de inspirar formas sempre distintas de representação e de estruturação do imaginário" (CESERANI, 2006, p. 122123), aportando ao gênero instrumentos novos, linguagem e uma concepção também nova de literatura.

Aceita como fantástica pelo próprio autor, "por falta de melhor nome", a narrativa de Julio Cortázar (1914-1984), objeto de reflexão neste estudo, caracteriza-se pela mudança nos paradigmas literários e culturais ao colocar em crise os pressupostos epistemológicos do leitor, oferecendo por meio de seus relatos uma nova forma de percepção da realidade. Construído com precisão rigorosa, o universo fantástico de Julio Cortázar inicia em 1951, com a publicação de Bestiário (1982), primeiro livro de relatos no qual já aparece a tônica do fantástico inserida na realidade objetiva. Presa ao real, a narrativa de Cortázar caracteriza-se por ser uma "escritura poliédrica, polimorfa, cujos planos da narração parecem refletir outros planos que reverberam em planos inesperados" (DAMAZIO, 2000, p.15). Para o próprio Cortázar,

A nossa realidade esconde uma segunda realidade (uma realidade maravilhosa), que não é nem misteriosa nem teológica, mas, ao contrário, profundamente humana. Ela por causa de uma longa série de equívocos permanece infelizmente escondida sob uma realidade pré-fabricada por muitos séculos de cultura, mas uma cultura pode produzir muitas grandes descobertas, mas também profundas aberrações, profundas distorções (apud, CESERANI, 2006, p. 123-124).

Em diversos relatos, Julio Cortázar apresenta uma predileção pelo excepcional, seja nos temas ou nas formas expressivas, impondo ao leitor um modo ambíguo e paradoxal de compreender a realidade, para além da percepção rotineira do "real". A situação causal específica, criada a partir de procedimentos narrativos, projeta uma nova luz sobre o fato banal que dessa forma é transformado em acontecimento dual e surpreendente. Nessa operação metafísica se altera o sentido da percepção para estabelecer uma nova forma de pensamento que é paradoxal e subversivo do senso comum. Assim, pelo caminho do não sentido, o autor/leitor adentra num sistema mais complexo de relações, aglutinante de

5 "[...] presentando en la forma de problemas, hechos anormales, irracionales o irreales, en contraste con hechos reales, normales o naturales". 


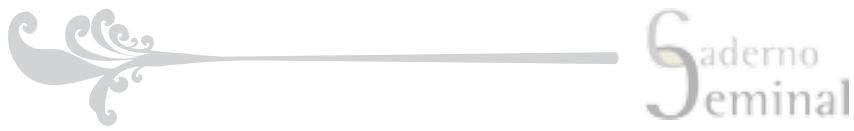

uma realidade infinitamente mais vasta, projetando dois planos do ser: um profundo e real, outro, multiplicidade infinita do vir a ser, vazio abismal em que o duplo é incluído como habitante.

A manifestação do excepcional, de uma ordem mais secreta e menos comunicável, cria um sentimento de ambiguidade no leitor ao se deparar com forças inexplicáveis provenientes de outros planos da realidade, que irrompem em nossa cotidianidade como se fossem sonhos ou alterações psíquicas da mente, para revelarem no espaço da ficção a sutil fronteira entre o real e o irreal. Na narrativa fantástica de Cortázar, a irrupção do 'outro' acontece, como já assinalamos, de forma trivial e prosaica, por meio de fatos insignificantes e corriqueiros colocados em situações estranhas, que alteram, por isso mesmo, nossa percepção do real. Como exemplos desse tipo de manifestações podemos encontrar em Bestiário (1951) ou Final do Jogo (1956), livros nos quais as projeções do estranho se expressam desde diferentes perspectivas: às vezes, como identidades duplicadas (La noche boca arriba, Distante, Axolot, continuidade dos parques), outras, como revelação da diferença (As portas ao céu, Ônibus, Bestiário, Depois do almoço), para ficar em alguns exemplos.

A diferença de contos em que se apresenta o estranho como algo inexplicável ou fora do espaço real, os relatos de Julio Cortázar postulam incerteza e ambiguidade a partir da justaposição de realidades numa duplicidade do ser. Em Distante (CORTÁZAR, 1986), por exemplo, o 'outro' é representado como dualidade, e o duplo se manifesta num mundo paralelo, correlato da realidade do relato. Alina Reyes, narradora protagonista relata sua história de vida num diário no qual registra, em primeira e terceira pessoa, as vozes e delírios de uma personalidade fragmentada que se funde e se confunde em Alina/mendiga, duplos de se mesma:

Não, horrível. Horrível porque abre caminho a esta que não é a rainha, e que outra vez odeio de noite. A essa que é Alina Reyes, não a rainha do anagrama; que será qualquer coisa, mendiga em Budapeste, frequentadora de prostíbulo em Jujuy ou criada em Quetzaltenango, em qualquer lugar distante e não rainha ${ }^{6}$ (CORTÁZAR, 1986, p. 36).

E mais adiante Alina Reyes afirma: "Porque a mim, à distante, não a querem" (CORTÁZAR, 1986, p. 38), ao se referir a sua própria identidade, revelando a troca de personalidades num jogo de vozes a partir das quais se constrói o relato. Dessa divisão emerge a descontinuidade de um sujeito fragmentado, projetando-se num outro plano da realidade. As personalidades se confundem na urdidura narrativa alimentando uma à outra e dando ao leitor a possibilidade de mover-se num horizonte de dimensões duplas no qual as sequências sistemáticas de "Eu" - "Ela" são vozes em concerto que ordenam a vida da protagonista e o desenvolvimento da história.

$6 \quad$ "No, horrible. Horrible porque abre camino a ésta que no es la reina, y que otra vez odio de noche. A esa que es Alina Reyes, pero no la reina del anagrama; que será cualquier cosa, mendiga en Budapest, pupila de mala casa en Jujuy o sirvienta en Quetzaltenango, cualquier lado lejos e no reina". 


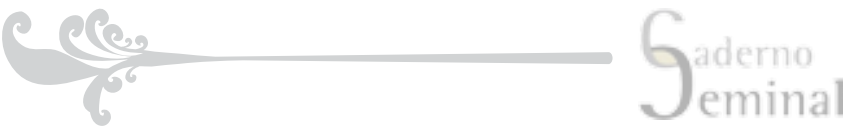

Dividido em duas partes, o relato narra simultaneamente a vida de Alina Reyes, mulher rica, frívola, que vive em Buenos Aires num ambiente de festas, luxo e excentricidades, e seu duplo, a 'distante'(Iejana), uma mendiga de Budapeste atormentada pela fome e o frio. Alina sente de maneira simultânea a dor e o sofrimento da mendiga, que é ela mesma,

Lembro-me que um dia pensei: 'Lá me batem, lá a neve entra em meus sapatos, e eu sei disto na hora, quando lá está me acontecendo eu fico sabendo na mesma hora. Mas por que na mesma hora em que está acontecendo? Talvez chegue tarde, talvez não tenha acontecido ainda. Talvez baterão nela daqui a quatorze anos, ou já é uma cruz e um número no cemitério de Santa Úrsula7 (CORTÁZAR, 1986, p. 42).

Ao final da história, produz-se a fusão das personalidades de Alina Reyes para dar lugar a outra voz que até o momento não tinha se apresentado na narração. Ao cruzar a ponte (lugar de encontro e separação), cria-se a passagem da interioridade à exterioridade, e é precisamente o momento da simbiose das duas personalidades que se acoplam para se dividir de novo de maneira imperceptível e surpreendente. Como se houvesse uma superposição de identidades, Alina convertida em mendiga grita:

Ao abrir os olhos (talvez gritasse agora) viu que se haviam separado. Agora, sim, gritou. De frio, porque a neve estava entrando por seus sapatos furados, porque andando a caminho da praça ia Alina Reyes, lindíssima em seu vestido cinzento, o cabelo um pouco solto contra o vento, sem voltar o rosto e andando8 (CORTÁZAR, 1986, p. 47).

Em La noche boca arriba (CORTÁZAR, 2004a), relato cuja história faz referência ao ritual asteca do sacrifício humano na época da 'guerra florida', é outro dos contos no qual Cortázar alude à dualidade do ser, mas a diferencia de Distante, - nesse caso vemos a duplicidade a partir da interpenetração de realidades temporais, do salto da interioridade (manifestada pela febre, o sonho, o pesadelo, a antiguidade pré-hispânica) - e à exterioridade (o acidente, o hospital, a vigília, a modernidade), revelando, assim, a luta interior do homem para atingir um desenvolvimento mais excelso de sua consciência.

No relato, os desdobramentos temporais se produzem num ir e vir de realidades estabelecidas a partir dos estados de sonho e de vigília, instaurando uma atmosfera onírica e surreal. Um homem do século XX que sofre um acidente de moto é internado num hospital, e em estado febril sonha ser um índio moteca que está sendo perseguido pelos astecas para sacrificá-lo aos deuses na guerra florida:

\footnotetext{
$7 \quad$ "Me acuerdo que un día pensé: 'Allá me pegan, allá la nieve me entra por los zapatos y esto lo sé en el momento, cuando me está ocurriendo allá yo lo sé al mismo tiempo. ¿Pero por qué al mismo tiempo? A lo mejor me llega tarde, a lo mejor no ha ocurrido todavía. A lo mejor le pegarán dentro de catorce años, o ya es una cruz y una cifra en el cementerio de Santa Úrsula".

8 "Al abrir los ojos (tal vez gritaba ya) vio que se habían separado. Ahora sí gritó. De frío, porque la nieve le estaba entrando por los zapatos rotos, porque yéndose camino de la plaza iba Alina Reyes lindísima en su sastre gris, el pelo un poco suelto contra el viento, sin dar vuelta la cara y yéndose".
} 
Como sono era curioso, porque estava cheio de cheiros e odores que nunca sonhou. Primeiro um cheiro pantanoso, pois do lado esquerdo da estrada começam os pântanos, o tremor de onde ninguém jamais voltou. Mas o cheiro cessou e em seu lugar veio uma fragrância composta e escura como a noite na qual fugia dos astecas. E tudo era tão natural, tinha que fugir dos astecas, que estavam á caça de homens, e sua única chance era se esconder no meio da selva, tomando cuidado para não afastar-se da estreita estrada que só eles, os Motecas, conheciam [...] Então pegou uma baforada do cheiro terrível que ele temia, desesperado saltou para frente. -Vai cair da cama, disse o paciente lado- Não pule muito meu amigo9 (CORTÁZAR, 2004a, p.228, tradução nossa).

Porém, em determinado momento do relato, o moteca também sonha ser um homem do século $X X$, que sofreu um acidente de moto e é internado num hospital. Os dois sonham ser outro, que é a mesma pessoa, mas no decorrer da história os limites entre o real e o sonho se diluem cada vez mais numa perspectiva em que fica difícil saber quem é o sonhador e quem é o sonhado:

Era difícil manter os olhos abertos, a sonolência foi mais forte do que ele. Fez um último esforço, com a mão boa esboçou um gesto em direção à garrafa de água; não chegou a tomá-la, seus dedos se fecharam em um vazio negro, e a passagem foi interminável, rocha trás rocha, com súbitas erupções avermelhadas, e ele de cabeça para acima gemeu vagamente porque o teto estava prestes a terminar, ascendia, abrindo-se como uma boca de sombra, os acólitos se levantavam e uma lua minguante caiu sobre seu rosto onde os olhos não queriam vê-la, desesperadamente fechavam-se e abriam tentando passar para o outro lado, redescobrir o teto de proteção da sala10 (CORTÁZAR, 2004a, p.234, tradução nossa).

Pelos pesadelos, o homem do século XX sabe da existência do índio moteca (duplo de si mesmo num outro estado de consciência), mas nega-se a reconhecêlo, lutando para se manter acordado. Ao mesmo tempo, o índio moteca quando é caçado e levado à força ao teocalli, e diante da iminência da morte debatese lutando por despertar, chorando para voltar ao hospital onde ele acredita estar sua verdadeira existência.

No jogo de temporalidades, podemos perceber duas perspectivas de interpretação: uma remete a caça dos astecas na guerra florida e os sacrifícios humanos na antiguidade pré-hispânica, outra representa a luta do homem da modernidade para sair da materialidade e atingir seu ser superior. O conflito gerado por

\footnotetext{
9 "Como sueño era curioso porque estaba lleno de olores y él nunca soñaba olores. Primero un olor a pantano, ya que a la izquierda de la calzada empezaban las marismas, los tembladerales de donde no volvía nadie. Pero el olor cesó, y en cambio vino una fragancia compuesta y oscura como la noche en que se movía huyendo de los aztecas. Y todo era tan natural, tenía que huir de los aztecas que andaban a la caza de hombre, y su única probabilidad era la de esconderse en lo más denso de la selva, cuidando de no apartarse de la estrecha calzada que sólo ellos, los motecas, conocían [...] Entonces sintió una bocanada horrible del olor que más temía, y saltó desesperado hacia adelante.-Se va a caer de la cama - dijo el enfermo de al lado-. No brinque tanto, amigazo".

10 "Le costaba mantener los ojos abiertos, la modorra era más fuerte que él. Hizo un último esfuerzo, con la mano sana esbozó un gesto hacia la botella de agua; no llegó a tomarla, sus dedos se cerraron en un vacío negro, y el pasadizo seguía interminable, roca tras roca, con súbitas fulguraciones rojizas, y él boca arriba gimió apagadamente porque el techo iba a acabarse, subía, abriéndose como una boca de sombra, los acólitos se enderezaban y de la altura una luna menguante le cayó en la cara donde los ojos no querían verla, desesperadamente se cerraban y abrían buscando pasar al otro lado, descubrir de nuevo el cielo raso protector de la sala".
} 


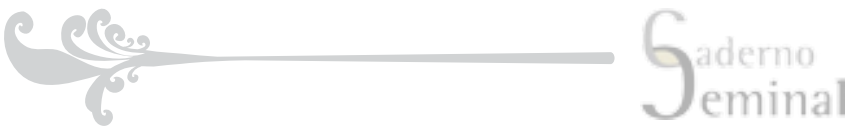

essa luta interior é o desafio existencial da consciência para transcender sua materialidade. Na persecução vivida pelo moteca, o 'cheiro da guerra' é o cheiro mais temido porque significa o enfrentamento inevitável com a morte, momento de purificação e revelação da verdade última. A purificação, símbolo da transcendência, revela a luta do homem por atingir um estado superior. $\mathrm{O}$ caráter antitético da consciência humana se estabelece precisamente nessa luta interior que surge do questionamento acerca da essência do homem.

Ao final da história, o narrador revela que o sonhador não é o homem do século XX, mas o índio moteca. No entanto, o caráter ambíguo do final deixa em aberto um jogo de possibilidades de interpretação em virtude de o próprio sonho poder representar a consciência do sonhador acidentado ou a consciência do índio moteca:

Conseguiu fechar suas pálpebras novamente, mas agora ele sabia que não iria acordar, que estava acordado, que o sonho maravilhoso tinha sido o outro, absurdo como todos os sonhos; um sonho no qual ele tinha andado pelas avenidas estranhas de uma cidade surpreendente ${ }^{11}$ (CORTÁZAR, 2004a, p.234, tradução nossa).

Nessa bipolaridade entre o sonho e a vigília, não podemos determinar com clareza quem é o sonhador e quem é o sonhado; sem embargo, sim, podemos estabelecer um eterno retorno entre sonhador - sonho - sonhador, passando nesses ciclos de sonho para estados de vigília.

Esse sentimento de estranheza e de angústia, que assalta o homem quando tem consciência de sua individualidade quando percebe que vive separado dos outros, também pode ser chamado de otredad. Nas palavras de Octavio Paz (1993, p. 36), a otredad "é a revelação da perda da unidade do ser do homem", sempre pensada como uma busca da identidade, do reconhecimento do eu. Para encontrar os diferentes fragmentos que conformam o multifacetado eu, é necessário estabelecer um plano paralelo à nossa realidade na qual o ser possa se manifestar plenamente.

A partir da consciência da otredad, realiza-se um processo de justaposição de realidades e transposição temporal que nos enfrenta com o novo, com o "outro", sendo forçados a reconhecer sua real existência. É precisamente essa vivência que acontece em 'Axolotl' - um relato que começa com uma terrível afirmação: "Houve um tempo em que eu pensava muito nos axolotl. la vê-los no aquário do Jardin des Plantes e ficava horas olhando-os, observando sua imobilidade, seus obscuros movimentos. Agora sou um axolotl"12 (CORTÁZAR, 2004a, p. 212, tradução nossa).

\footnotetext{
$11 \quad$ "Alcanzó a cerrar otra vez los párpados, aunque ahora sabía que no iba a despertarse, que estaba despierto, que el sueño maravilloso había sido el otro, absurdo como todos los sueños; un sueño en el que había andado por extrañas avenidas de una ciudad asombrosa [...]".

12 "Hubo un tiempo en que yo pensaba mucho en los axolotl. Iba a verlos al acuario del Jardin des Plantes y me quedaba horas mirándolos, observando su inmovilidad, sus oscuros movimientos. Ahora soy un axolotl."
} 
De pouco em pouco, o narrador vai ficando hipnotizado por esses pequenos anfíbios, que descobriu "por azar" um dia no aquário do Jardin des Plantes e, à força de visitá-los diariamente, começa um diálogo mudo e intenso com eles, obcecado pela ideia de que essas larvas queriam se comunicar com ele, de que haveria neles qualquer coisa de terrivelmente humano:

Comecei vendo nos axolotl uma metamorfose que não conseguia anular uma misteriosa humanidade. Eu os imaginei conscientes, escravos de seu corpo, infinitamente condenados a um silêncio abissal, a uma reflexão desesperada. Seu olhar cego, o diminuto disco de ouro inexpressivo e sem dúvida, terrivelmente lúcido, me penetrava como uma mensagem: <<salve-nos, salve-nos>>. Eu me surpreendia murmurando palavras de consolo, transmitindo ingênuas esperanças. Eles continuavam me olhando, imóveis [...] Nesse instante eu sentia uma dor surda; talvez me vissem, captavam meu esforço em penetrar no impenetrável de suas vidas. Não eram seres humanos, mas em nenhum animal havia encontrado uma relação tão profunda comigo ${ }^{13}$ (CORTÁZAR, 2004a, p. 215, tradução nossa).

Um axolotl, que no passado foi um homem, agora mantém uma estranha comunicação com seu antigo corpo, transformação, como já vimos, revelada desde o início do relato. Mas, à medida que a narração avança, a situação torna-se inquietante e o processo de osmose vai transformando o narrador num axolotl: "Não há nada de estranho nisso; logo desde o primeiro instante eu senti que alguma coisa me ligava a eles, algo muito longínquo e esquecido que, no entanto, continuava a nos unir"14 (CORTÁZAR, 2004a, p. 212, tradução nossa).

O processo de metamorfoses do homem-axolotl ou do axolotl-homem já se encontra presente na própria palavra axolotl, que em nahuatl significa larva, e em latim larva significa também máscara ou fantasma. Máscara ou fantasma de quem, senão dele próprio. Eis o abismo insondável que o eu deve vencer para chegar a ser aquele que não é: a "otredad", a excisão primordial:

Sem transição, sem surpresa, vi minha cara contra o vidro, ao invés do axolotl vi minha cara contra o vidro, eu a vi fora do aquário, eu a vi do outro lado do vidro. Então ela se distanciou e eu compreendi. Só uma coisa era estranha: continuar pensando como antes, saber. Dar-me conta disso foi, no primeiro instante, como sentir o horror de quem é enterrado vivo e logo desperta para seu destino [...] Ou eu estava também nele, ou todos nós pensávamos como um homem, incapazes de qualquer expressão, limitados ao resplendor dourado de nossos olhos que olhavam a cara do homem colada no aquário ${ }^{15}$ (CORTÁZAR, 2004a, p. 217, tradução nossa).

\footnotetext{
13 Empecé viendo en los axolotl una metamorfosis que no conseguía anular una misteriosa humanidad. Los imaginé conscientes, esclavos de su cuerpo, infinitamente condenados a un silencio abisal, a una reflexión desesperada. Su mirada ciega, el diminuto disco de oro inexpresivo y sin embargo terriblemente lúcido, me penetraba como un mensaje: <<sálvanos, sálvanos>>. Me sorprendía musitando palabras de consuelo, transmitiendo pueriles esperanzas. Ellos seguían mirándome, inmóviles [...] En ese instante yo sentía como un dolor sordo; tal vez me veían, captaban mi esfuerzo, por penetrar en lo impenetrable de sus vidas. No eran seres humanos, pero en ningún animal había encontrado una relación tan profunda conmigo".

14 "No hay nada de extraño en esto, porque desde un primer momento comprendí que estábamos vinculados, que algo infinitamente perdido y distante seguía sin embargo uniéndonos".

15 "Sin transición, sin sorpresa, vi mi cara contra el vidrio, en vez del axolotl vi mi cara contra el vidrio, la vi fuera del acuario, la vi del otro lado del vidrio. Entonces mi cara se apartó y yo comprendí. Sólo una cosa era extraña: seguir pensando como antes, saber. Darme cuenta de eso fue en el primer momento como el horror del enterrado vivo que despierta a su destino [...] O yo estaba también en él, o todos nosotros pensábamos como un hombre, incapaces de expresión, limitados al resplandor dorado de nuestros ojos que miraban la cara del hombre pegada al acuario".
} 


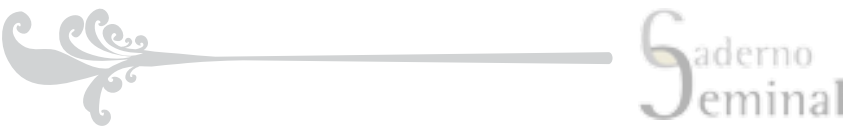

O inquietante adquire maior intensidade no último parágrafo do conto quando se invertem totalmente as perspectivas, deixando o leitor estupefato perante tão incrível paradoxo. Desta vez é o narrador que se encontra no aquário e pensa no homem que de vez em quando o vem visitar, cada vez menos agora, já liberto da sua terrível obsessão: "E nesta solidão final para a qual ele não voltará mais, resta-me o consolo de pensar que talvez ele escreva qualquer coisa sobre nós; vai pensar que inventa um conto e vai escrever tudo isso sobre axolotls"16 (CORTÁZAR, 2004a, p. 218, tradução nossa).

No desfecho do relato, a ficção torna-se ambígua quando o axolotl, com mente de homem, conclui que o homem que ele foi, no passado, vai escrever uma história sobre a transmigração de sua mente tal como se tivesse sido imaginada. Assim, a visão do narrador do conto se entrelaça com a visão do axolotl do narrador, e desse entrelaçamento surge a significação do conto.

Um jogo de possibilidades emerge da contemplação que o narrador faz do outro ser ao ponto de se fusionar com a consciência do sujeito que contempla e do sujeito contemplado. O eu do narrador é homem e axoltl ao mesmo tempo, e ao reencarnar no outro compreende sua dupla condição mental, sua nova forma, em que pode apreciar a sutileza desse seu novo estado de consciência, eu e outro, essa otredad que sou eu:

Como a única coisa que faço é pensar, pude pensar muito nele. Eu me dou conta de que desde o princípio permanecemos em comunicação, que ele se sentia mais do que nunca unido ao mistério que era sua obsessão. Mas as ligações entre ele e eu estão cortadas, porque o que era sua obsessão é agora um axolotl, alheio à sua vida de homem. Creio que no princípio eu era capaz de regressar a ele, de certo modo - ah, apenas de certo modo - e manter desperto o seu desejo de nos conhecermos melhor. Agora sou definitivamente um axolotl, e se penso como homem é somente porque todo axolotl pensa como um homem dentro de sua imagem de pedra rosa ${ }^{17}$ (CORTÁZAR, 2004a, p. 217-218, tradução nossa).

A metamorfose vivida pelo narrador do relato explica a estranheza que produz em nós a leitura do conto. A angústia e a ambigüidade, experimentadas pelo leitor, surgem da possibilidade de que esse mesmo fato possa suceder em seu próprio mundo, ao se dar conta que o sinistro nos espreita, e em qualquer momento pode transpassar os limites do texto, tomando conta de nossa realidade. Resta ao leitor decidir em qual plano da realidade vai se instalar.

\footnotetext{
$16 \quad$ "Y en esta soledad final, a la que él ya no vuelve, me consuela pensar que acaso va a escribir sobre nosotros, creyendo imaginar un cuento va a escribir todo esto sobre los axolotl".

17 "Como lo único que hago es pensar, pude pensar mucho en él. Se me ocurre que al principio continuamos comunicados, que él se sentía más que nunca unido al misterio que lo obsesionaba. Pero los puentes están cortados entre él y yo, porque lo que era su obsesión es ahora un axolotl, ajeno a su vida de hombre. Creo que al principio yo era capaz de volver en cierto modo a él - ah, sólo en cierto modo - y mantener alerta su deseo de conocernos mejor. Ahora soy definitivamente un axolotl, y si pienso como hombre es sólo porque todo axolotl piensa como un hombre dentro de su imagen de piedra rosa."
} 


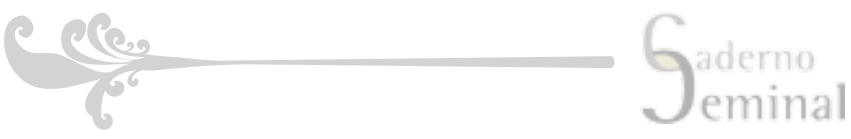

\section{Considerações Finais}

No corpo textual, as vozes se conjugam para dar lugar a uma sucessão de imagens que revelam e ocultam os sentidos perdidos do texto. Na multiplicidade de percursos, a linguagem, zona marginal na qual tudo é possível, transforma o tempo e o espaço "real" em território do imaginário, recuperando em outro plano o que a realidade nos furta. Assim, a linguagem faz da escrita um espelho cuja função seria "refletir" ou "representar" a língua. Porém, ao final esse espelho termina traindo a imagem refletida: junto a ela faz emergir outra imagem, outra cena que é o espaço do imaginário: "Espaço fantasmático onde o desejo tece as figuras de sua monstruosidade, fazendo desse denso tecido textual uma figura monstruosa em si mesmo, que recorta sua diferença contra o fundo homogêneo de todo saber e discurso"18 (PEREIRA, 1985, p. 12, tradução nossa).

No imaginário cortazariano a narrativa potencializa e corporiza fantasmas por meio de um duplo e contraditório movimento de forças em choque, que não emergem da luz, mas das obscuras zonas do sonho e da mente projetadas no espaço da realidade para preservar a possibilidade do 'real'. Da mesma forma, o duplo manifesta-se como figura metamorfoseada no texto para fazer emergir um corpo textual que tenta fusionar-se no tecido virtual da escrita como identidade ou diferença. Um que é também idêntico e diferente ao mesmo tempo, reflexo ou sombra de si mesmo. Condição dilacerada do ser, suspensa, sem poder recobrar sua verdadeira identidade, situada num limite movediço que divide e separa. Nem cá nem lá, zona de incertezas, lugar do imaginário e, mesmo assim, real, porque em sua ambiguidade a ficção torna possível a sua impossibilidade.

As vertigens do duplo cortazariano revelam novas realidades nas quais "eu sou outro eu", desdobrado ou transvestido nos fragmentos de mim mesmo. Nessa poética, não há lugar para as leis da identidade, só contradição e exclusão da lógica e da razão. Porém, se concebemos o real como uma dimensão em que também se alberga "o irreal", a lógica causal primeira transforma-se em "aparição", permitindo assim a manifestação de uma presença invisível e silenciosa, antes oculta pela lógica causal do real, que agora se revela para dar espaço a essa nova realidade, mas complexa e ilimitada em sua multiplicidade ficcional. Não um reflexo nem um sonho ou devaneio, simplesmente uma aparição no lugar impalpável da ficção.

18 "Espacio fantasmático, pulsional, en el que el deseo teje las figuras de su monstruosidad, haciendo a su vez de ese denso tejido textual una figura monstruosa en sí mismo, que recorta su diferencia contra el fondo homogéneo de todo saber y todo discurso". 


\title{
ANOTHER PLANE OF BEING: THE POETRY OF DUPLICITY IN JULIO CORTÁZAR'S FANTASTIC NARRATIVE
}

\begin{abstract}
:
Diverse reports of Julio Cortázar present a predilection for the exceptional, whether in themes or the form of expression, imposing upon the reader an ambiguous and paradoxical manner of comprehending reality, going beyond the routine perception of "real". The specific causal situation, created through narrative processes, projects a new light upon the trivial fact that this form is transformed into dual and surprising happening. In this metaphysical operation, the sense of perception towards establishing a new form of thinking which is paradoxical and subversive of common sense is altered. Thus, along the path of nonsense, the author/reader enter a more complex relationship system, bound to an infinitely vaster reality on which two planes of being are projected; one profound and real and the other the infinite multiplicity of coming to be, an abysmal emptiness in which the dual is included as an inhabitant. Based on previous considerations, this study seeks to achieve poetic reflection upon the presence of the dual in the fantastic narrative of Julio Cortázar, understanding this concept as a synonym and correlate to fiction.
\end{abstract}

\section{KEYWORDS:}

Fantasy Literature; Dual; Reports; Julio Cortázar.

\section{REFERÊNCIAS}

ALAZRAKI, J. En busca del unicornio: los cuentos de Julio Cortázar. Elementos para una poética de lo neofantástico. Madrid: Editorial Gredos, 1983. (Coleção Biblioteca Románica Hispánica. II. Estudios y Ensayos, 324).

Tres formas del ensayo contemporáneo: Borges, Paz, Cortázar. Revista de la Universidad de México. México: Nueva Época, n. 17, v. XXXVIII, p. 19-23, set, 1982.

BARRENECHEA, A. M. Ensayo de una tipología de la literatura fantástica. Caracas: Monte Ávila Editores, 1978.

BLANCHOT, M. O livro por vir. São Paulo: Martins Fontes, 2005 (Coleção Tópicos).

CESERANI, R. O fantástico. [Tradução de Nilton Cezar Tridapalli]. Curitiba: Editora UFPR, 2006. 
CORTÁZAR, J. Bestiario. 4. ed. México: Editorial Nova Imagen, 1982.

Bestiario. Tradução (revista) de Remy Gorga, filho. Rio de Janeiro: Editora Nova Fronteira S.A. 1986.

"La noche boca arriba". In: CORTÁZAR, J. Los relatos, 1: ritos. 4.reimpressão. Madrid: Alianza Editorial, S.A., 2004a.

. "Continuidad de los parques". In: CORTÁZAR, J. Los relatos, 2: juegos. 4.reimpressão. Madrid: Alianza Editorial, S.A., 2004b.

. "Axolotl". In: CORTÁZAR, J. Los relatos, 1: ritos. 4. reimpressão. Madrid: Alianza Editorial, S.A., 2004a.

DAMAZIO, R. "O poliedro Cortázar". In: Cult, Revista Brasileira de Literatura. São Paulo: No. 39, ano IV, outubro, 2000, p.14-19.

FOUCAULT, M. El lenguaje al infinito. Córdoba: Ediciones de Dianus, 1986 (Série de Ensayo y Crítica. Otras Inquisiciones).

PAZ, O. Itinerario. México: Fondo de Cultura Económica, 1993.

El Mono Gramático. In: Obra Poética (1935-1988). México: Editora Seix Barral, S.A., 1990, p.505-582.

PEREIRA, A. Deseo y escritura. México: Premiá Editora de Libros, 1985 (Coleção La red de Jonás/Estudios).

PEZZONI, Enrique. "Borges: la revuelta sigilosa". In: Revista de la Universidad de México. México: Nueva Época, n. 12, v. XXXVIII, abril, 1982, p. 45-47. 